\title{
El Movimiento Nadaísta en Colombia
}

I. BREVE BOSQUEJO DE LA POESÍA COLOMBIANA DEL SIGLO XX.

L

A poesía colombiana ha seguido una trayectoria más o menos uniforme, salvo algunas excepciones; se ha señalado como una característica de las letras colombianas una corrección y un cuidado en la forma de raigambres humanisticas y académicas que frecuentemente han constituido un freno para las corrientes innovadoras y para los influjos foráneos.

Contra estos obstáculos han de enfrentarse quienes deseen dar un rumbo distinto y novedoso a las letras en Colombia. Esto explica que movimientos de vanguardia como el Ultraísmo, el Creacionismo, etc., hayan tenido tan escaso eco en la poesía colombiana de los últimos cuarenta años.

Hacia I9ro y una vez extinguido el Modernismo, surgió en Colombia la llamada generación "del Centenario", por haber coincidido con la celebración de los primeros cien años de vida independiente; la formaban Porfirio Barba Jacob, Luis Carlos López, Eduardo Castillo y José Eustasio Rivera, entre los más importantes. Respecto a su producciön poco nuevo aportaron y más bien fueron fulgores crepusculares del rubendarismo decadente. Quizás el más apreciable del grupo sea Luis Carlos López, a quien el crítico Ebel Botero le señala "un lugar de transición por lo menos en lo relativo a la métrica. Es ésta poco variada, muy conservadora, sin quererlo su autor, y al mismo tiempo algo revolucionaria, sin tal vez proponérselo"."1

1 Ebel, Botero, 5 poetas colombianos (Manizales: Biblioteca de Escritores Caldenses. Tercera época. Vol. 19, 1964). p. 127. El crítico mexicano Arqueles Vela, miembro fundador del grupo estridentista, por su parte, lo considera como un iniciador del posmodernismo. Véase: Arqueles Vela, Luis Carlos López iniciador del posmadernismo. (México: Colección Actuales, 1963 [folleto de 18 páginas]. 
Las pocas influencias vanguardistas que en Colombia dejaron alguna huella se encuentran parcialmente en la obra de varios poetas que integraron el grupo "Los Nuevos" entre I9I9 y 1925, grupo que, según Néstor Madrid Malo "representa apenas un tímido intento de ruptura con el modernismo", "2 entre los que sobresale la obra de Luis Vidales Suenon timbres (1926), donde vemos técnicas surrealistas. Integran este grupo poetas bien diferenciados unos de otros y entre los cuales difícilmente encontraremos una constante común; son ellos: el musical y malabarista de palabras León de Grieff; el profundo, sereno y delicado Rafael Maya; el poeta de lo terrestre y de lo cósmico Germán Pardo García, entre los sobresalientes.

Posterior a este grupo aparecieron los "Piedracielistas", hacia I935, inspirados en el libro Piedra y cielo de Juan Ramón Jiménez, de los cuales mencionaremos a Eduardo Carranza, Jorge Rojas, Antonio Llanos, Aurelio Arturo y Gerardo Valencia.

Constituyeron una reacción ante los vientos vanguardistas que amenazaban la calma y la serenidad en la que se mecían las letras colombianas; fue una actitud poética de recobración según afirma el crítico argentino Alfredo $A$. Roggiano refiriéndose a la figura central de este grupo: "Eduardo Carranza y los 'piedracielistas' se dieron como programa esa doble recuperación: la dimensión del hombre en su tiempo y en su mundo y la dimensión del hombre y de su mundo en su historia, en su tradición cultural". 3

El mismo crítico anota como características de este grupo, su afirmación vital y su profundo sentido nacional, americano e hispánico, manifestando siempre una actitud cristiana y católica.

No tardó en aparecer una serie de continuadores de la estética piedracielista a quienes la crítica los ha agrupado bajo el nombre genérico de "pospiedracielistas", entre los que mencionaremos a Fernando Charry Lara, Daniel Arango, Oscar Echeverri Mejía, Andrés Olguín, Helcías Martán Góngora y la poetisa Meira del Mar, en quienes hay una marcada influencia de los poetas de la generación peninsular del veinte, en especial de Vicente Aleixandre y Luis Cernuda, de quienes es un gran admirador Charry Lara, su mejor exponente.

Ya hacia I950 surgió un grupo de poetas jóvenes, llenos de ímpetu y ambición, quienes empezaron a publicar en la revista Semanca cuader-

2 Néstor Madrid-Malo, "Itineratio de la poesía colombiana". Inter-American Review of Bibliograpby. "Washington, septiembre de 1962, Núm. 19, p. 247.

3 Alfnedo A. Roggiano, "Eduardo Carranza y la nueva poesía colombiana". Humanitas. Universidad Nacional de Tucumán, Argentina. Año II, N ${ }^{\circ}$ 5. 1954. p. 230. 
nillos de poesías, razón por la cual se les conoce como "Cuadernícolas". Produjeron una obra poética de indiscutible mérito y constituyeron. un coro de voces fuertes y delicadas que cantaban las profundas conmociones espirituales de esos años. Fueron ellos, entre otros: Fernando Arbeláez, poeta que expresó en su canto el caos circundante; Jorge Gaitán Durán, vate del asombro, de la tristeza y de la muerte; Eduardo Cote Lamus, quien recoge en su obra desde los motivos más simples e intimistas hasta los más intrincados e indescifrables; Carlos Castro Saavedra, de voz profética y clamorosa ante la injusticia social y el desasosiego. Lástima que sus mejores voces: Gaitán Durán y Cote Lemus, hayan desaparecido temprana y trágicamente.

Hasta el grupo de los "Cuadernícolas" la poesía colombiana presenta, aunque en actitudes variadas y diversas, una evolución constante que nunca se ha desviado del cauce común, cuyo lecho, como expresé antes, han sido la moderación, la pureza idiomática y la emoción lírica.

Posterior al Nadaísmo, tema de este estudio, ha aparecido el "Testimonialismo", movimiento poético que tiende a exponer la injusticia social, de inspiración democrática y cristiana, que se formó alrededor de la revista Téstimonio, fundada en Bogotá por los dominicos y cuyo mejor representante es Ramiro Lagos con su libro Testimonio de las horas grises, publicado en 1964 .

Pero el movimiento verdaderamente revolucionario de los últimos años ha sido el Nadaísmo del cual pasamos a ocuparnos.

\section{ORÍGENES.}

El Nadaísmo como movimiento literario aparece en los años 1958 y r959 en las ciudades de Medellín, Cali y Manizales; en los años posteriores se esparce por otras ciudades colombianas e invade a la ciudad capital con el traslado de su iniciador y máximo representante, Gonzalo Arango.

Es el Nadaísmo un movimiento estrictamente literario y aún no se ha manifestado su influencia en las artes plásticas o en la música. En el campo de la literatura se ha expresado primordialmente en la poesía, aunque tanto en la novela como en el teatro hay obras de tipo nadaista.

Los primeros brotes nadaístas tuvieron lugar en Medellín, ciudad tradicionalișta en todo sentido, y cuna del costumbrismo literario en Colombia. Integran la plana mayor del Nadaísmo, además de su jefe Gonzalo Arango, los siguientes: J. Mario, Amilkar U., Alberto y Eduatdo Escobar, Elmo Valencia, Mario Rivero, Darío Lemos, Guillermo Trujillo, Diego 
León Giraldo, y X-504. Todos eran jóvenes entre 19 y 24 años, por lo general bachilleres que iniciaron estudios universitarios para interrumpirlos luego no por falta de capacidades sino por desilusión ante la vaciedad y la inoperancia de sistemas educativos y profesores anquilosados.

\section{Medios DE EXPRESIón.}

Como carecian de fondos económicos pata la necesaria divulgación del movimiento y por no tener el apoyo de casas comerciales o instituciones culturales para fundar su propio órgano de difusión, los nadaístas optaron por atraer la atención mediante el escándalo público o el disparate.

Empezaron por reunirse en un establecimiento público, "La heladería Versalles", situada en la parte céntrica de la ciudad; allí tomaban café, fumaban, discutían y luego daban alaridos hasta atraer la atención de los transeúntes; luego empezaron a usar cabellos largos, trajes juveniles vistosos, en especial camisa roja, y en ningún momento vestimentas serias tales como corbatas, chalecos, o traje completo.

Durante la noche embadurnaban las paredes de los edificios públicos con letreros y consignas nadaístas; hacían sus orgías, improvisaban sus discursos en las vías públicas, los que eran diatribas contra lo tradicional, lo hermético y burgués de la sociedad imperante; viajaban de ciudad en ciudad para dialogar y atraer a los jóvenes, y en fechas y lugares determinados, previamente difundidos, incineraban públicamente docenas de libros, en especial de tendencia romántica o costumbrista.

En esta forma atrajeron la atención de la gran prensa en cuyas páginas, a manera de noticia burlona, aparecieron sus desmandes, sus manifiestos y sus poemas.

Poco a poco se han hecho conocer luchando contra la incomprensión, el academicismo y los valores preconcebidos de la élite intelectual colombiana. No podriamos decir que han triunfado totalmente ni que se les han abierto las puertas de los conciliábulos literarios; hubo triunfos esporádicos como la concesión del primer premio de teatro a Gonzalo Arango en el Festival Nacional del Arte por su obra Sexo y saxofón, lo cual causó gran polémica. Otros nadaístas apenas ahora empiezan a publicar sus libros mientras que la gran mayoria no ha pasado de figurar en pobres antologías.

Han surgido divergencias dentro del movimiento y algunos de sus miembros han solicitado en telegrama público a su iniciador y jefe, su 
inmediato suicidio para mayor gloria del movimiento. En lugar de suicidarse, Gonzalo Arango ha optado por dedicarse más al estudio de las letras; es un incansable lector y es asiduo colaborador y crítico de varios periódicos y revistas, y actualmente se desempeña como libretista de la televisora nacional.

\section{Significado y alcances del nOMbre.}

Desde un comienzo se denominaron a sí mismos nadaístas, puesto que buscaban expresar la Nada y en la nada se inspiraban. Así, dice Gonzalo Arango:

Nada termina nunca, nada empieza. Todo es presencia. Todo existe en trance de revelación. También lo que no existe, existe en las posibilidades infinitas de la nada. La nada es el porvenir del Ser, como la tierra es el porvenir del hombre.4

Son pues, los poetas del momento, del paso del no ser al ser, de esa Gran Nada que deja de serlo en el poema. Parten de la convicción de que siempre hay un misterio en las cosas, el cual no ha sido revelado y al que los poetas buscan expresar. Nadaísmo es un sacerdocio poético: es vivificar con la palabra lo muerto por ell desgaste cotidiano; es un canto al caos y a la destrucción que fructifican en vida. Su lema parece ser el destruirlo todo, el volver a la Nada y allí plantar los nuevos cimientos de un universo resucitado.

Son los nadaístas los poetas de la confusión, de la morbosidad, de la locura, del dolor y del sufrimiento; de la guerra, del absurdo y de la creación.

Su programa es ambicioso y complejo; su desarrollo lento y confuso; su producción poca y de escaso valor artístico. De ese griterío inicial sólo perduran algunas voces que insisten en la nadería de la poesía.

\section{DoCtRIna POÉtica de este MOVimiento.}

Al leer los distintos conceptos expresados por Gonzalo Arango en varios de sus escritos podemos reducir en un esquema básico las ideas poéticas y artísticas propias del Nadaísmo.

4 Gonzalo Arango, "La poesía nadaísta", en 13 poetas nadaístas (Medellín, 1963), p. 1. (A esta edición pertenecen las citas posteriores). 
a) El principio de la creación gratuita de la obra poética, la cual aparece sin mayor esfuerzo, sin lógica, sin plan alguno y simplemente como producto del azar:

Esta belleza no tiene la culpa de ser así $[\ldots]$ No es para almas platónicas, equilibradas o razonables. No tiene nada que ver con la nostalgia de un mundo mejor, ni con el sueño de otro mundo. Se insta'ó en su tiempo, porque era allí donde tenía que instalarse, bajo un cielo de dolor, brutalidad y agonía. (G. A., op. cit., p. I).

Es esta pocsía un producto gratuito del caos; para ser poeta nadaísta sólo se necesita papel, lápiz y deseos de reflejar ese caos en lo que se escribe. Expresar el fracaso, el hastío sensual, la desilusión, la crisis de valores y afrontar lo que salga sea bello o grotesco, sublime o vulgar, artístico o ramplón, y todo esto como un esfuerzo por recuperar el mundo de la nada; ese mundo inocente, primigenio, inmaculado y siempre nuevo.

Entiéndase el término creación gratuita con todas sus reservas, pues hay que ser víctimas de ese caos y sentirse afligido para expresarlo.

b) El antihistoricismo. Los nadaístas no quieren ningún nexo con el pasado o con el futuro; no proyectan su obra ni se sienten obligados a ello. Su poesía muere con el momento que se vive y renace con el instante que empieza. Es la poesía de la fugacidad, del hoy, del ahora. Ignoran por completo las escuelas o movimientos anteriores; temen al efecto congelador de la historia, símbolo éste de lo estático frente a lo dinámico:

La Historia está en liquidación. Se traslada con sus cacharros axiológicos y sus utensilios inútiles, y pone en manos del impostor más fuerte las mejores tradiciones del espíritu, los bellos dones del alma, sus éxtasis, su soledad, sus libertades adorables y sus glorias. (Ibid., p. I).

c) La concepción no utilitaria del arte. No buscan estos poetas un fin determinado en la obra artística; no conciben utilitariamente el arte ni conciben la doctrina de un arte puro. A la pregunta ¿Para qué sirve el arte?, Arango contesta:

No tengo ídea para qué sirve el arte. A mí me sirve para encamar 
mujeres. ¿Quiere una justificación? Ahí va: Soy un poeta subversivo que no gana para it a los burdeles. 5

d) El antidogmatismo. El Nadaísmo va contra todo dogmatismo; el dogma supone la aceptación de un estado prestablecido en el que escasos horizontes se le brindan al poeta. Para el nadaísta lo esencial es su libertad en la cual su obra se realiza y sin la cual cualquier creación resultaría hueca y limitada:

Nada de someternos a la autonomía creadora. [...] Al diablo con Aristóteles y sus opuestos. Para los Nadaístas es más simple: su libertad es tirarse de un décimo piso en protesta al Dogma de la Gravitación de la tierra. Si le da la gana". (Arte y webelión, s. p.)

e) La no sujeción dél arte a una moral o a una ética. Esto sería comprometerse y para los nadaístas la obra poética no ha de obedecer a consignas o a ideologías; esto iría contra la libertad necesaria para la creación artística. A este respecto Gonzalo Arango dice: "El arte y la ética cuando se juntan hacen el eclipse de la belleza. $[\ldots] \mathrm{El}$ arte bajo cualquier servidumbre se vuelve mecánica". (Arte y rellelión, s. p.).

Los anteriores son, a grandes rasgos, los principios básicos del Nadaísmo, cuyos ejecutores rechazan la destrucción masiva, la guerra; se sienten víctimas de un proceso ilógico y abrupto en el que se pasa del caballo al avión supersónico; de la vida provincial al cosmopolitismo.

El nadaísta ve el caos del mundo y exclama: "En este manicomio residen muchedumbres de locos, lujuriosos y alienados. La civilización es la tumba en que vivimos". (G. A., op. cit., p. 2).

\section{POET'A Y POESÍA.}

Ante esá oscura y caótica realidad, el poeta no toma una actitud ni romántica ni escapista; su misión es la de reflejar en su obra el maremágnum que le circunda y darnos "esa imagen de belleza airada, rota, dudosa", fiel símbolo de la Nada. Arango agrega: "Un mundo en crisis y desintegración produce una belleza de tránsito, provisional en lo absoluto y cotrespondiente a la turbación que le inspira". (Ibid., p. 2).

De ahí que la poesía nadaísta no sea un ejemplo de perfección artís-

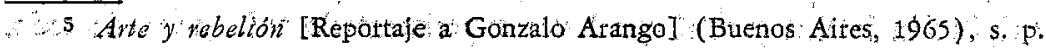


tica y que su anhelo no sea el alcanzar la armonía del clásico porque ésta no existe en el mundo actual.

He aqui su definición de poesía: "La poesía no es distinta de la vida, pues es creación, testimonio del mundo y al mismo tiempo trascendencia". (p. 2).

Subrayamos tres palabras: creacion, testimonio y trascendencia.

Creación porque en ese caos de la realidad el pocta es "un buscador de imágenes para crear un mundo unificado". (p. 3). Su misión es la de reclasificar el mundo y las cosas; la de retornar a éstas su inocencia y valor iniciales; la de infundirles la vida que han perdido en envenenada atmósfera. Testimonio porque la obra del poeta ha de ser una especie de cardiograma de la época en que vive y a este respecto leemos:

No se le reprocha a Cristo, a Esquilo, a Dante, a Goethe, la fastuosa inspiración de sus respectivos universos poéticos. Ellos reseñaron con fidelidad irrecusable una rebelión metafísica, el tránsito del hombre por esta tierra hacia su propio cielo de salvación. (p. 3 ).

Más que evasión o evocación nostálgica encontramos una intensidad vital en esta poesía; hav una aceptación o un rechazo-la sctitud no importa - sicmpre sincero de la realidad; el poeta es un testigo ocular y un sujeto paciente de la vida civilizada y su poesía es la respuesta a esa vida.

Trascendencia porque si la respuesta del poeta es fiel, sincera, humana, entonces sus palabras no caerán en el vacio y reflejarán luz al alma de los lectores, sin necesidad de retóricas gastadas, ni de aspavientos melodramáticos sino en un diálogo directo que comunique ese halo de vitalidad que emerge del poeta.

Dentro de esta poética no vemos un rechazo a los avances científicos, por el contrario, el poeta nadaista trata de mantenerse a la altura de dichos avances:

La fantasía y el mito no son ya fantasmas de la imaginación, sino certidumbres maravillosas de los sentidos [...] Gagarín, el Prometeo moderno, ha robado de nuevo el secreto a los dioses insumisos, $y$ la luz a los cielos arcanos $[\ldots] \mathrm{Y}$ el poeta, fundiría en su canto la sombra y la luz de estas bodas entre la ciencia del cosmos y la poesía cósmica. (p. 4).

Son, pues, poetas del momento presente; su poesía será entonces una palpitación intensa y vital que busca experimentarlo todo, anegarlo todo, 
absorberlo todo sin caer en la ebriedad eufórica del modernista, ni en la desesperación nostálgica del romántico. Su concepto de la belleza reside en lo dinámico de ésta; en su capacidad de renovarse y de manifestarse, en la que reside su energía creadora:

La belleza no es eterna sino en la medida en que muere para vivir: se eclipsa en la palabra y resucita del silencio, del que retoma su energía creadora. (p. 5).

El poeta pasa a ser otro Cristo, sobre cuyos hombros lleva el destino de todos los hombres y cuya misión es "lograr la alianza entre el Ser y la Nada, y triunfar en la Unidad. Y la función de la auténtica poesía no es otra que convocar los seres a la existencia". (p. 6).

Finalmente, observemos la posición del poeta nadaísta ante el lenguaje; aquél cree en la palabra desnuda, directa, sin oropeles literarios; nada de juegos hiperbólicos o de metáforas estrambóticas. No; para el nadaísta,

El prestigio de la palabra nunca está cancelado. Resucita de las tumbas y de sus viajes por las tinieblas, y regresa a la luz del sol, fiel a su misión de comunicar lo incomunicable y dar sentido a lo inexplicable. Ella da testimonio de lo que hay bajo el cielo y detrás de la muerte. Vive con los hombres y después de ellos. (p. 6).

Lo anterior es a grandes rasgos la doctrina nadaísta merced a la cua'l se ha dado una poesía que nos deja perplejos por su procacidad, su desdén por lo convencional, su frescura y su entereza. Los nadaístas escriben sobre lo que se les venga en gana sin preocuparse por ética, estética - moral alguna. Bástenos mencionar algunos de los títulos de sus poemas: "Tu ombligo, capital del mundo", "Carretera Panamericana", "La policía de Manizales", "J. Mario despide energía radiante a su amada", "Canción de un insecto", "Flor de idiotismo", "Poema ro-42", "El telegrama te cuero", "Jairo contra mi ingle", "Visita de la ballena a X-504", "Vamos a comer libélulas amargas"., "Los dioses podridos", etcétera.

\section{Conclusiones.}

Después de un análisis espectral del Nadaísmo poco, muy poco, quedaría en su favor, en lo que se refiere a su aportación artística. La misma crítica de los jóvenes intelectuales colombianos los rechazan. Leamos una de las más recientes: 
El Nadaísmo es la otra cara del tradicionalismo burgués, una farsa alimentada por las clases dominantes, por sus periódicos y sus salones; es una actitud de falsa rebeldia, que por desgracia ha confundido a mucha juventud con inclinaciones avanzadas. ${ }^{6}$

Nuestro punto de vista no es tan negativo; creemos que él Nadaísmo ha permido $\mathrm{y}$ ha sido el promotor de un resurgimiento en las letras colombianas. Dejemos a un lado sus escándalos y su actitud irreverente ante lo tradicional, ya que ésta ha sido el arma obligatoria de los movimientos revolucionarios; es cierto que del grupo nadaísta es poca la producción literaria que tenga un valor artístico, pero a todos ellos les corresponde el valor de haber desenfrenado la tormenta cuyos rayos despertaron a los jóvenes intelectuales del adormecimiento cotidiano. Ellos han promovido encuestas, han organizado discusiones y han luchado hombro a hombro con la crítica comprometida que ha impedido la divulgación y el triunfo de nuevas figuras literarias. Ellos han sido los más valientes y heroicos defensores de la literatura de vanguardia. Por última vez escuchamos al jefe de este grupo, refiriéndose a los valores consagrados e inamovibles de las letras colombianas actuales:

Porque mientras ustedes duermen sobre los laureles nosotros velamos; porque mientras ustedes se anquilosan y vuelven sus miradas a la colonia con un romanticismo nostálgico y cobarde, nosotros sabemos que todas las desgracias de la patria, de la política, de la cultura, radican en el escandaloso divorcio de vuestro pensamiento caduco, conformista y contemplativo, de un lado, y esta arrolladora realidad nueva que desborda los estrechos y antiguos moldes en que se tiene confinada la historia colombiana?

Es esta actitud combativa la que en nuestro concepto constituye el valor intrínseco del Nadaísmo. Ellos participan en cuanto concurso literario se presenta; leen cuanto libro cae en sus manos, y en especial, mantienen vivo ese anhelo de superación y de perfeccionamiento, que son símbolos seguros de una obra en realización, de la que ya se han dado variados frutos de óptima calidad que han sido galardonados con primeros premios.

\footnotetext{
6. Ftancisco Posada, "Ideas sobre el arte nacional y el arte realista", Letras nacionales (Bogotá, 1965), $\mathrm{N}^{\circ}$ 0, p. 25.

7 Gonzalo Arango, "Cómo ser jurado en tres lecciones", "Lecturas dominicales", El Tiempo, Bogatá (junio 6 de 1965), p. 3.
} 


\section{APENDICE}

Textos COMPLEMENTARIOS PARA LA ESTÉtica DEL NADAÍsmo.

Carta a J. Mario. [...] Un vacío terrible, no tengo deseos siquiera de morit. Imposible ir a Cali por ahora. Además, las ciudades son iguales, apestan. Yo sugicro para mi gravedad el mar. Sí, es lo último (...) Mirar alejarse las gaviotas y un poco de ron en la ventana recibiendo el sonido de barcos pesqueros que regresan? Sí, quiero mar para nosotros, dioses podridos de ciudad. Estoy reventando esta tarde.

Darío Lemos

El Crisol, 28 de octubre de $1962, p$. Io

El nadaúsmo es, $y$ basta.

Dije al empezar que el Nadaísmo no propone soluciones, sino dudas, pues la Duda es un principio creador. Dar soluciones abstractas que no resuelvan problemas concretos, es puro idealismo, utopías platónicas en las que no estamos dispuestos a invertir un minuto de nuestra vida física, ni de nuestra santa y perecedora energía espiritual.

Pues bien: no se hagan ilusiones, pierdan la fe en el Nadaísmo. No tenemos soluciones adecuadas para nada (...) Nadie sabe qué es el Nadaísmo, ni yo tampoco. Si alguien sospechara lo que es, ya nos habrian metido a la cárcel', o al manicomio. Nos conviene entonces que sea algo misterioso y que se sepa poco de él.

Sospecho en todo caso, que el Nadaísmo es lo Desconocido. Además, el Nadaísmo no se explica por una lógica deductiva, sino que se vive, es una vivencia de la razón contra la Razón Pura.

Si trato de esbozar un esquema que defina nuestra conspiración, no setá a nombre de un método, sino de un desorden, porque el Nadaísmo no es una filosofía sistemática, sino una pasión existencial, un furor, una rebelión $[\ldots]$.

En esencia reclamamos una lealtad a nuestro tiempo, y para nosotros mismos. En esta exigencia radica nuestra rebelión y nuestra locura $(\ldots)$

$\mathrm{La}$ literatura por el hecho de ser trascendencia es 'compromiso con el hombre, con la vida y con el mundo. Nosotros nos oponemos a com. prometerla con una fracción del nundo, con una orilla del ser, con un 
sector de la condición humana y social. No queremos hipotecarla a un compromiso parcial, servicial, mezquino, ni embanderarla, porque no queremos que la literatura sirva intereses inferiores a sus grandes posibilidades de comprometerse con todo, $\mathrm{v}$ antes que nada, con ella misma. Porque el primer compromiso de la literatura es con la literatura. El arte que sirve a la vida y a la belleza es el arte auténtico. El arte que sirve a intereses particulares es un arte enajenado.

Gonzalo Arango

Suplemento literario de $\mathrm{El}$ Crisol, Noviembre II, I962, pp. 9 y 16

\section{El artista violento.}

(Palabras inaugurales en la exposición de pintura de Yesid Montaña). Soy un nadaísta, soy un mago, soy un profeta de la nueva oscuridad. Seamos sinceros. ¿Cuál es la función primordial dél artista? Es ésta: violar la figura, violar el lenguaje, violar la materia, violar lo que no veamos ni oímos, violarlo todo para gestar un mundo diferente, donde haya claridad, donde el amor sea mejor repartido, donde no falte nada ni en la mesa ni en la cama (...) El artista tiene que ser violento, de otra manera pasará a la historia como un mequetrefe.

EL MONJE LOCO

El Expreso, Cali, junio 27, 1964, p. 9

\section{Déscomposición de la poesía.}

En el principio la poesía nadaísta era informe y vacía. A pesar de esto, sobre ella gravitaba el espíritu de una legitima rebelión $[\ldots]$ Lo primero que hicimos fue lanzar a la basura el mechón de cabellos de la mujer amada, borrar de nosotros la exaltación heroica, las tentaciones anecdóticas o polémicas, el ritmo, rima, tema, forma y objetivo. Enlazábamos y cruzábamos palabras con sentido de crucigrama. Para nosotros escribir poesía era sentarnos a urdir botones sin objetivo definido, como maniáticos en una guerra nuclear. No nos comprometimos con nada; por el contrario, nos divorciamos de todo (...) Eramos unos temibles bichos ambulantes que ibamos de azotea en azotea vomitando todo el cansancio 
de nuestra espasmódica maravillosa (...) Le temiamos a la palabra lucha como a una ducha de agua bendita helada (...) Pero algunos de nosotros, de pronto, resolvieron que en nuestra poesía el sentido de la lucha podía asumir la forma de la protesta. Pero no protesta contra un sistema determinado, sino contra todo aquello que coartara, que calumniara nuestra pasión humana por la vida. Hasta los más radicales decidimos, entonces, escribir una literatura beligerante en nuestros ratos de ocio, en aquellos que nos dejaba nuestra diaria consagración a los bajos instintos y el arte irrazonable.

\section{J. MARIo}

El Expreso, Cali, abril 4, x964, p. 9

Yo soy X-504.

La X es también para preguntar quién soy. Es una interrogación $(\ldots)$ Soy el nombre falso de la verdad.

$\mathrm{X}-504$, número de presidiario (...) No me parece malo llamarme X, pues Cristo se llamaba Cruz, y una Cruz es una $\mathrm{X}$ andando en una sola pata $(\ldots)$

$\mathrm{X}-50_{4}$ es neutro. Por su solo enunciado no se sabe su género, si es un borracho o un bombardero y recuerda "la dicha de no tener un nombre" que decía Virginia Woolf. Pero X-504 es un poeta. Lo que es un hombre lo han dicho muchos. Lo que es un poeta nadie lo sabe. ¿Y para qué sirve un poeta? Sirve para hacer el amor. (...)

$\mathrm{X}-504$ existe para que Jaime Jaramillo Escobar pueda vivir libremente, sin el peso de la literatura y de la admiración.

$x-504$

El Expreso, Cali, ibid, p. 9. 


\section{ANTOLOGIA}

LOS NADAÍSTAS.

Los nadaístas invadieron la ciudad como una peste:

de los bares saxofónicos al silencio de los libros de los estadios olímpicos a los profilácticos

de las soledades al ruido dorado de las muchedumbres

de sur a norte

a'l encenderse de rosa el día

hasta el advenimiento de los neones

y más tarde la consumación de los carbones nocturnos

hasta la bilis del alba.

Va solo hacia ninguna parte

porque no hay sitio para él en el mundo

no está triste por eso

le gusta vivir porque es tonto estar muerto

o no haber nacido.

Es un nadaísta porque no puede ser otra cosa está marcado por el dolor de esta pregunta

que sale de su boca como un vómito tibio

de color malva y emocionante pureza:

"Por qué hay cosas y no más bien Nada?"

Este signo de interrogación lo distingue

de otras verdades y de otros seres.

El es él como una ola es una ola

lleva encima su color que lo define como revolucionario

como es propia la liquidez del agua

del hombre ser mortal

del viento ser errante

del gusano arrastrarse a su agujero

de la noche ser oscura como un pensamiento sin porvenir.

Ha teñido su camisa de revolución

en los resplandores de los incendios 
en el asesinato de la belíeza

en el suicidio eléctrico del pensamiento

en las violaciones de las vírgenes.

o simplemente en el barrio pobre de los tintoreros.

Lleva su Camisa Roja como un honor

como un cielo lleva su estrella

como un semáforo produce su luz intermitente

de catástrofe

como una envoltura de "pall-mall"

perfumando su pecho de adolescente.

El Nadaista es joven y resplandece de soledad

es un eclipse bajo los neones pálidos

y los alambres del telégrafo

es, en el estruendo de la ciudad

$\mathrm{y}$ entre sus rascacielos

el asombro de una flor teñida de púrpura

en los desechos de la locura.

Tiene el peligro de los labios rojos y los polvorines

mira los objetos con ojos tristes de aniversario

es ell terror de los retóricos

y los fabricantes de moral

es sensitivo como un gonococo esquizofrénico

inteligente como un tratado de magia negra

ruidoso como una carambola a las dos de la mañana

amotinado como un olor de alcantarilla

frívolo como un cumpleaños

es un monje sibarita que camina sin temblor

a su condenación eterna

sobre zapatos de gamuza.

Sufre el vértigo de los sacudimientos

electrónicos del jazz

y las velocidades contra-reloj

corazon de rayo de voltio que estalla

en el parabrisas de un Wolkswagen

deseando la mujer de tu prójimo. 
Se aburre mortalmente pero existe.

No se suicida porque ama furiosamente fornicar jugar billar-pool en las noches interminables brindar ron en honor a su existencia estirarse en los prados bajo las lunas metálicas
no pensar
no cansarse
no morirse de felicidad
ni de aburrimiento.

Es espléndido como una estrella muerta

que gira con radar en los vagos cielos vacios

No es nada pero es un Nadaista

Y está salvado!

Gonzalo arango.

EL ARCO DE ILA OREJA

lo que pasa es que llueve

no hay razón de estar triste ni de nada

tiene usted la palabra

está usted vivo

lo que pasa es que llueve

$y$ que no llueve

-hay fragancia de trueno en su palabra

- hay ritmo de tragedia en su mirada

-hay amaneramiento

-hay armonía

-pide usted más?

(lo que pasa es que llueve todavía)

- pero viéndolo bien está usted joven

-tiene anhelos-dinero 
-tiene novia

- usted piensa que todo está salvado

...y está salvado

(lo que pasa es que llueve

y muere

y hiede)

J. Mario.

\section{DiNAMIA DE LA COMUNIÓN}

Todo el mes llovido, precipitaciones celestes, frágiles arcángeles de agua durante toda la noche cayendo como heridos de una batalla astral. El temblor entre las sábanas, nuestro pasado bajo la calidad de conversaciones. Saliste durante la mañana $y$, al regreso con la cara toda como si te mirase tras un vidrio, trizas de luz en la mejilla, cabello al viento sudoroso.

AMILKAR U.

LA ROSA NEGRA

Al fín, me hastié de sueños azules y desperté.

Desperté y salí.

Salí.

Los carpinteros me vieron

y golpearon el lomo de una mesa.

Un hombrecillo jorobado de barba 
y de mirada de gato o de mecánico murió.

Un tango se cuela trabajosamente por las rejas de las ventanas de las casas.

Los yanquis dijeron que eran superiores.

La rosa negra

que se aferró a mi ropa

tiene mil recuerdos como Salomé.

Eduardo Escobar.

Los gallos Del General

Durante la guerra murieton

los gallos de colores de los gencrales

(y también 5.000 hombres).

Los gallos eran la alegria/de los ejércitos

Cuando la cresta les sangraba

y las pechugas desnudas,

no habia quien dejara de sufrir.

Los gallos dormían

sobre los fusiles almacenados

y cantaban cuando empezaban los días

$y$ de noche, engañados,

cuando se filtraba por las carpas

La luz del fuego de la guerra.

Cantaban también

en la pequeña pelea de ellos.8

Guillermo Trujillo.

Pablo González Rodas

West Virginia Univer'sity

813 poetas nadaistas. (Medellín, 1963. Editor: Gonzalo Salazar). Al corregir las pruebas de este trabajo, mi maestro Alfredo Roggiano me da a conocer el número 18 de El corno emplumado. (México, abril de 1966), en donde se publica una selección de la poesía nadaísta en Colombia (pp. 167-187). 